\title{
Visually guided inspiration breath-hold facilitated with nasal high flow therapy in locally advanced lung cancer
}

Citation for published version (APA):

Peeters, S. T. H., Vaassen, F., Hazelaar, C., Vaniqui, A., Rousch, E., Tissen, D., Van Enckevort, E., De Wolf, M., Ollers, M. C., van Elmpt, W., Verhoeven, K., Van Loon, J. G. M., Vosse, B. A., De Ruysscher, D. K. M., \& Vilches-Freixas, G. (2021). Visually guided inspiration breath-hold facilitated with nasal high flow therapy in locally advanced lung cancer. Acta Oncologica, 60(5), 567-574.

https://doi.org/10.1080/0284186X.2020.1856408

Document status and date:

Published: 04/05/2021

DOI:

10.1080/0284186X.2020.1856408

Document Version:

Publisher's PDF, also known as Version of record

Document license:

Taverne

Please check the document version of this publication:

- A submitted manuscript is the version of the article upon submission and before peer-review. There can be important differences between the submitted version and the official published version of record.

People interested in the research are advised to contact the author for the final version of the publication, or visit the DOI to the publisher's website.

- The final author version and the galley proof are versions of the publication after peer review.

- The final published version features the final layout of the paper including the volume, issue and page numbers.

Link to publication

\footnotetext{
General rights rights.

- You may freely distribute the URL identifying the publication in the public portal. please follow below link for the End User Agreement:

www.umlib.nl/taverne-license

Take down policy

If you believe that this document breaches copyright please contact us at:

repository@maastrichtuniversity.nl

providing details and we will investigate your claim.
}

Copyright and moral rights for the publications made accessible in the public portal are retained by the authors and/or other copyright owners and it is a condition of accessing publications that users recognise and abide by the legal requirements associated with these

- Users may download and print one copy of any publication from the public portal for the purpose of private study or research.

- You may not further distribute the material or use it for any profit-making activity or commercial gain

If the publication is distributed under the terms of Article $25 \mathrm{fa}$ of the Dutch Copyright Act, indicated by the "Taverne" license above, 


\title{
Visually guided inspiration breath-hold facilitated with nasal high flow therapy in locally advanced lung cancer
}

\author{
Stephanie T. H. Peeters, Femke Vaassen, Colien Hazelaar, Ana Vaniqui, \\ Eva Rousch, Debby Tissen, Esther Van Enckevort, Michiel De Wolf, Michel \\ C. Öllers, Wouter van Elmpt, Karolien Verhoeven, Judith G. M. Van Loon, \\ Bettine A. Vosse, Dirk K. M. De Ruysscher \& Gloria Vilches-Freixas
}

To cite this article: Stephanie T. H. Peeters, Femke Vaassen, Colien Hazelaar, Ana Vaniqui, Eva Rousch, Debby Tissen, Esther Van Enckevort, Michiel De Wolf, Michel C. Öllers, Wouter van Elmpt, Karolien Verhoeven, Judith G. M. Van Loon, Bettine A. Vosse, Dirk K. M. De Ruysscher \& Gloria Vilches-Freixas (2021) Visually guided inspiration breath-hold facilitated with nasal high flow therapy in locally advanced lung cancer, Acta Oncologica, 60:5, 567-574, DOI: 10.1080/0284186X.2020.1856408

To link to this article: https://doi.org/10.1080/0284186X.2020.1856408

View supplementary material $\asymp$ 


\title{
Visually guided inspiration breath-hold facilitated with nasal high flow therapy in locally advanced lung cancer
}

\author{
Stephanie T. H. Peeters ${ }^{a}$, Femke Vaassen ${ }^{a}$, Colien Hazelaar ${ }^{a}$, Ana Vaniqui ${ }^{a}$, Eva Rousch ${ }^{a}$, Debby Tissen ${ }^{a}$, \\ Esther Van Enckevort ${ }^{\mathrm{a}}$, Michiel De Wolf ${ }^{\mathrm{b}}$, Michel C. Öllers ${ }^{\mathrm{a}}$, Wouter van Elmpt ${ }^{\mathrm{a}}$, Karolien Verhoeven ${ }^{\mathrm{a}}$, \\ Judith G. M. Van Loon ${ }^{a}$, Bettine A. Vosse ${ }^{c}$, Dirk K. M. De Ruysscher ${ }^{a}$ and Gloria Vilches-Freixas ${ }^{a}$

\begin{abstract}
${ }^{a}$ Department of Radiation Oncology (MAASTRO), Maastricht University Medical Center, GROW, Maastricht, The Netherlands; ${ }^{b}$ Department of Anesthesiology and Pain Therapy, Maastricht University Medical Center, Maastricht, The Netherlands; 'Department of Pulmonology, Maastricht University Medical Center, Maastricht, The Netherlands
\end{abstract}

\begin{abstract}
Background and purpose: Reducing breathing motion in radiotherapy (RT) is an attractive strategy to reduce margins and better spare normal tissues. The objective of this prospective study (NCT03729661) was to investigate the feasibility of irradiation of non-small cell lung cancer (NSCLC) with visually guided moderate deep inspiration breath-hold (IBH) using nasal high-flow therapy (NHFT).

Material and methods: Locally advanced NSCLC patients undergoing photon RT were given NHFT with heated humidified air (flow: $40 \mathrm{~L} / \mathrm{min}$ with $80 \%$ oxygen) through a nasal cannula. IBH was monitored by optical surface tracking (OST) with visual feedback. At a training session, patients had to hold their breath as long as possible, without and with NHFT. For the daily cone beam CT (CBCT) and RT treatment in $\mathrm{IBH}$, patients were instructed to keep their $\mathrm{BH}$ as long as it felt comfortable. OST was used to analyze stability and reproducibility of the $\mathrm{BH}$, and $C B C T$ to analyze daily tumor position. Subjective tolerance was measured with a questionnaire at 3 time points.

Results: Of 10 included patients, 9 were treated with RT. Seven (78\%) completed the treatment with NHFT as planned. At the training session, the mean BH length without NHFT was $39 \mathrm{~s}$ (range 15-86s), and with NHFT 78s (range 29-223s) $(p=.005)$. NHFT prolonged the BH duration by a mean factor of 2.1 (range 1.1-3.9s). The mean overall stability and reproducibility were within $1 \mathrm{~mm}$. Subjective tolerance was very good with the majority of patients having no or minor discomfort caused by the devices. The mean inter-fraction tumor position variability was $1.8 \mathrm{~mm}(-1.1-8.1 \mathrm{~mm} ; \mathrm{SD} 2.4 \mathrm{~mm})$.

Conclusion: NHFT for RT treatment of NSCLC in BH is feasible, well tolerated and significantly increases the breath-hold duration. Visually guided $\mathrm{BH}$ with OST is stable and reproducible. We therefore consider this an attractive patient-friendly approach to treat lung cancer patients with RT in $\mathrm{BH}$.
\end{abstract}

\section{ARTICLE HISTORY}

Received 30 July 2020

Accepted 22 November 2020

\section{KEYWORDS}

Lung cancer; breath hold; radiotherapy; surface scanning

\section{Background and purpose}

Due to breathing, lung tumors and surrounding organs move, and this may pose a challenge for radiotherapy (RT) treatments. Methods taking motion into account, such as internal target volume (ITV) or midventilation/midposition approaches using a $4 \mathrm{D}-\mathrm{CT}$ may result in larger margins, potentially leading to higher normal tissue doses and toxicity [1]. Breath-holding is an attractive strategy to minimize movements during RT as this may lead to a more reliable target coverage with smaller margins, and together with the larger lung volumes with lower densities, IBH may decrease the normal lung tissue doses and toxicity, and in some cases allows for curative treatment of larger lung tumors without exceeding dose-constraints [2-4]. In addition, proton RT might benefit from IBH, as anatomical shifts caused by breathing can lead to severe over- and underdosage [5].
However, the lung function of lung cancer patients may be impaired (e.g. because of chronic obstructive pulmonary disease (COPD), or as a direct result of the disease), making it potentially difficult to treat them in $\mathrm{IBH}$. Techniques supporting IBH might make it a feasible approach for those with a less favorable performance status.

A widely used technique for $\mathrm{BH}$ assistance is active breathing control $(A B C)$, but $B H$ durations are usually rather low, around $20 \mathrm{~s}$ [6-8]. A second example is high frequency percussive ventilation (HFPV) that administers small volumes of air at high pressure and frequency resulting in prolonged $\mathrm{BHs}$ of 5-10 min [9], but this device requires trained personnel, and evidence for safety is very little so far. Parkes et al. used a simple mechanical ventilator where pre-oxygenation was administered with mechanically induced hypocapnia through a facemask [10]. The mean $\mathrm{BH}$ duration in 30 volunteers was $6 \mathrm{~min}$ [11], but a substantial blood pressure rise 
was seen and therefore caution has to be taken in patients with cardiovascular comorbidity [12].

In this study, we investigated the use of nasal high-flow therapy (NHFT), a simple noninvasive system, providing controlled oxygen concentrations and low levels of positive pressure via a nasal cannula (Fisher\&Paykel Healthcare Ltd, Auckland, New Zealand) [13]. A nasal cannula might be more patient-friendly compared to a mouthpiece or facemask used in the previously mentioned methods [9-12]. NHFT is increasingly used as ventilatory support and improves oxygenation in diverse patient groups. It was shown to be safe in the home setting and in several clinical situations and patient populations, such as in neonatal and pediatric intensive care, in COPD patients, and in apneic conditions under general anesthesia [14-16]. This device has however, to the best of our knowledge, never been used in the context of $\mathrm{BH}$-support in RT. We hypothesized that supporting $\mathrm{BH}$ with NHFT will allow robust RT treatments of moving targets in a broad patient population allowing $\mathrm{BHs}$ that are longer, stable and reproducible during a whole treatment course, and will be well tolerated by the patients.

\section{Material and methods}

\section{Patients}

In this prospective study (NCT03729661), non-small cell lung cancer (NSCLC) patients with locally advanced stage III or oligometastatic disease treated with radical intent RT were included. Exclusion criteria were performance status WHO $>2$, hypercapnic COPD patient $(=\mathrm{PaCO} 2>45 \mathrm{mmHg})$. The institutional ethics committee approved the study.

\section{Preparation}

After having signed informed consent, a training session of 45 min was planned to familiarize the patients with the devices, define the voluntary $\mathrm{BH}$ level and test the maximal duration of a BH without and with NHFT (Figure 1(A)). NHFT was administered with Optiflow ${ }^{\mathrm{TM}}$ nasal high flow therapy using the AIRVO device (Fisher\&Paykel). This noninvasive system administers low levels of positive pressure via a nasal cannula. We administered the airflow at a volume of $40 \mathrm{~L} / \mathrm{min}$ with $80 \%$ of oxygen, at a temperature of $34^{\circ} \mathrm{C}$. Patients were immobilized supine in treatment position on a chest board (MacroMedics $^{\circledR}$, Waddinxveen, The Netherlands) with the arms above the head. They were instructed to breathe in and hold their breath to a level that felt comfortable. The chosen moderate IBH level was provided to the patient through visual feedback with virtual reality (VR) goggles using an OST system installed in the CT (Sentinel from C-RAD ${ }^{\circledR}$, Uppsala, Sweden) and treatment room (Catalyst HD from $\left(-R A D^{\circledR}\right.$ ). The $B H$ level was measured with OST at the xiphoid process. The width of the $\mathrm{BH}$ gating window, corresponding to the IBH level, was set at $3 \mathrm{~mm}$. Patients performed at least two voluntary BHs without NHFT, followed by at least two BHs with NHFT, with the instruction to hold the breath as long as possible (Figure 1(A)). After every $\mathrm{BH}$, patients indicated when they were ready for the next $\mathrm{BH}$, and after start of NHFT there was at least one minute of rest before starting $\mathrm{BH}$. After training session, two planning $\mathrm{CT}$ scans were performed, one in $\mathrm{BH}$ with $\mathrm{NHFT}$, and one 4DFDG-PET/CT scan in free breathing (FB). The first was used for planning the treatment with NHFT, the latter to create a back-up plan if needed. Throughout all sessions (training and treatment), a transcutaneous $\mathrm{CO}_{2}$-meter (TCM4 ${ }^{\circledR}$ from Radiometer) with ear sensor was used to continuously monitor transcutaneous carbon dioxide tension $\left(\mathrm{tcpCO}_{2}\right)$, oxygen saturation $\left(\mathrm{SpO}_{2}\right)$ and heart rate $(\mathrm{HR})$.

For each patient, the predicted forced expiratory volume in $1 \mathrm{~s}$ (FEV1) was obtained with spirometry in upright sitting position.

\section{Treatment planning}

The prescribed RT dose was $60 \mathrm{~Gy}$ in $2 \mathrm{~Gy}$ fractions for concurrent chemoradiation, and 57.75-66Gy in $2.75 \mathrm{~Gy}$ for sequential chemoradiation or RT alone. The planning target volume (PTV) margin in the BH plan with NHFT was $8 \mathrm{~mm}$ for the primary tumor, and $5 \mathrm{~mm}$ for lymph nodes. For the back-up plan in FB individual PTV-margins for the primary tumor were calculated based on the $4 \mathrm{D}-\mathrm{CT}$, and were on average $8.3,9.1$ and $8.3 \mathrm{~mm}$ in left-right (LR), cranio-caudal (CC) and anterior-posterior (AP) directions respectively [1]. Treatment techniques consisted of volumetric modulated arc therapy or a hybrid technique with AP-PA beams and arcs (using Eclipse TPS version 15.5), which were delivered with a linear accelerator (Truebeam, Millenium ${ }^{\mathrm{TM}}$ 120-leaf MLC, Varian, Palo Alto, USA).

\section{Treatment}

Patients were imaged and treated in $\mathrm{IBH}$, supported by NHFT, with visual feedback from OST system using VR goggles. An IBH cone-beam CT (CBCT) was used for daily image guidance with registration based on carina or bones at the discretion of the treating radiation-oncologist. In contrast to the training session, for the treatment, patients were instructed to hold their breath for the time it felt comfortable and stable.

The imaging or treatment beam was interrupted as soon as the $\mathrm{BH}$ level moved outside the $3 \mathrm{~mm}$ tolerance window, which was done mainly manually for the first 5 , and automatically for the last 4 patients when this interface between linac and OST became available.

The number of BHs needed per session was recorded. The thoracic surface was monitored continuously by the OST system and compared with an initially acquired reference surface using a surface threshold of $12 \mathrm{~mm}$. A new baseline was taken at the beginning of each fraction and the gating window was automatically set at a relative distance from this baseline by the Catalyst software. After couch translations an update of the actual live image may be necessary. Also the isocenter position and reference surface (body contour) were retrieved from the DICOM-RT plan and structure files. The Catalyst software predicted the isocenter position 
(A)
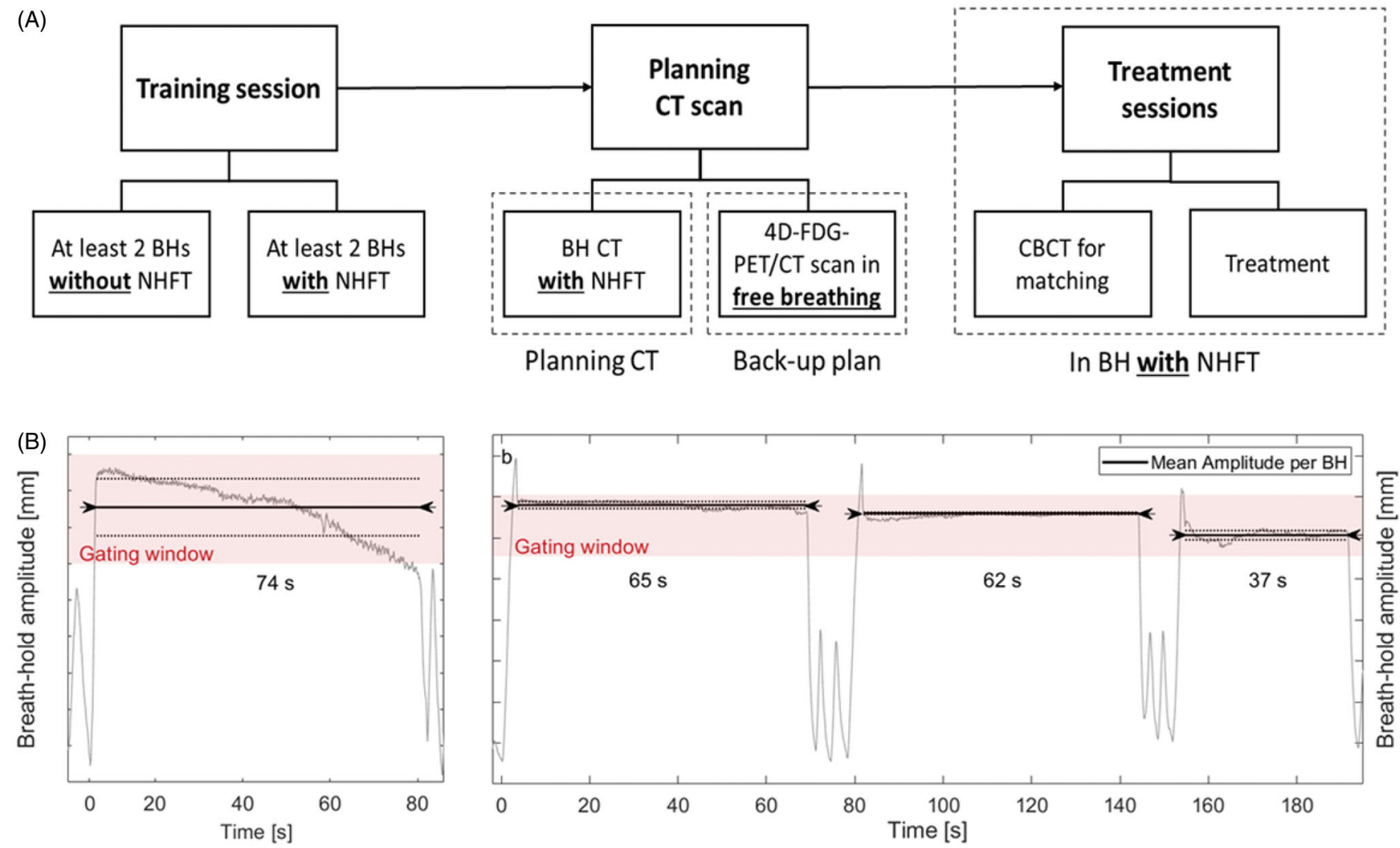

Figure 1. (A) Flow chart of the study. (B) Examples of BHs in two patients where the BH signal, monitored by the OST system is represented by the gray line. The pink area shows the gating window of $3 \mathrm{~mm}$. The black line indicates the level of the mean amplitude per $\mathrm{BH}$, and the dotted line is the \pm SD. The arrows on the black line show the $\mathrm{BH}$ length (x-axis). The beginning and end of each $\mathrm{BH}$ were defined manually. Overshoots at the beginning of a $\mathrm{BH}$ as seen in (B), were excluded, and the signal was included from the local minimum on. The graph on the left shows an example of an unstable $\mathrm{BH}$, but with the signal still within the gating window. The second patient on the right has three very stable BHs with small intra-BH SD. The change in level of the black line between BHs represents the reproducibility. BH: breath-hold; CBCT: cone-beam CT; NHFT: nasal high-flow therapy.

instantaneously based on the live surface and was calculated and visualized using a threshold tolerance of $5 \mathrm{~mm}$ for potential isocenter shifts.

\section{Analyses}

The primary endpoint was feasibility of the treatment, defined as the proportion of patients able to complete the whole treatment (CT-scan and treatment sessions) in $\mathrm{BH}$ with NHFT. Sample size calculation is based on the approach for a single stage phase II clinical trial, where the aim is to determine a confidence interval $(\mathrm{Cl})$ around the primary endpoint that excludes the threshold for poor feasibility while containing the aim for good feasibility [17]. The poor feasibility threshold is set at $33 \%$ while $75 \%$ would constitute good feasibility. Inclusion of 9 patients is sufficient for this purpose. If 6 or more patients complete the treatment successfully, the lower border of the $95 \% \mathrm{Cl}$ (from alpha 0.05) will exclude 0.33, showing a feasible treatment. If less than 6 patients complete the treatment successfully, the upper border of the $80 \% \mathrm{Cl}$ (from power 0.80 ) will exclude 0.75 , making the treatment not feasible. Taking into account a dropout of $10 \%$, the sample size was defined at 10 patients. Reasons for failure resulting in stopping of the treatment with NHFT may be subjective intolerance of NHFT, unable to perform a $\mathrm{BH}$, unstable $\mathrm{BH}$, unreproducible $\mathrm{BH}$, or patient refusing further treatment with NHFT.
Secondary endpoints were subjective tolerance, increase in maximal $\mathrm{BH}$ length during training session, stability and reproducibility of $\mathrm{BH}$, and daily $\mathrm{BH}$-depth. Subjective tolerance was measured at 3 time points (after training session, first and last treatment fraction) using a questionnaire with 6 items to be scored on a 5-point scale from 0 (no discomfort) to 5 (maximal discomfort): general discomfort, discomfort from nasal cannula, goggles, ear clip, dry throat or $\mathrm{BH}$. Differences in $\mathrm{BH}$ length during the training session were calculated with a Wilcoxon Signed Rank Test, with a $p$-value $\leq .05$ considered significant. The correlation of FEV1 with BH length was calculated with the Spearman's rank correlation coefficient.

The stability (or intra-BH variability) and reproducibility (or inter-BH variability) were calculated using OST. For stability, first the standard deviation (SD) of the amplitude of each $\mathrm{BH}$ was calculated, and this was averaged over all $\mathrm{BHs}$ per patient. For the reproducibility, the mean amplitude of each $\mathrm{BH}$ was first calculated, and for each patient the SD was then calculated over all BHs (Figure 1(B)). For overall stability and reproducibility, these results were averaged over all patients. $\mathrm{BHs}$ for imaging and treatment were analyzed together.

Differences in total lung volumes between planning FB-CT (represented by the $50 \%$ exhale phase of the $4 \mathrm{D}-\mathrm{CT}$ ) and IBH-CT were analyzed using a Wilcoxon Signed Rank Test.

To analyze the interfractional differences in daily $\mathrm{BH}$ depth we used an AP distance as a surrogate because the 
Table 1. Patients' characteristics.

\begin{tabular}{|c|c|}
\hline & $N=10$ \\
\hline Mean age (years) (range) & $67(60-74)$ \\
\hline \multicolumn{2}{|l|}{ Gender } \\
\hline Male & 6 \\
\hline Female & 4 \\
\hline \multicolumn{2}{|l|}{ WHO performance status } \\
\hline 0 & 3 \\
\hline 1 & 5 \\
\hline 2 & 2 \\
\hline \multicolumn{2}{|l|}{ Stage (TNM 8) } \\
\hline Stage IIIA & 3 \\
\hline Stage IIIB & 3 \\
\hline Stage IIIC & 2 \\
\hline Stage IVA & 1 \\
\hline Stage IVb & 1 \\
\hline \multicolumn{2}{|l|}{ Primary tumor location } \\
\hline Upper lobe & 8 \\
\hline Middle lobe & 0 \\
\hline Lower lobe & 2 \\
\hline FEV1 (\%pred): mean (range) & $66(24-94)$ \\
\hline \multicolumn{2}{|l|}{ Smoking status } \\
\hline Never smoker & 0 \\
\hline Former smoker & 6 \\
\hline Active smoker & 4 \\
\hline \multicolumn{2}{|l|}{ Treatment $(n=9)^{\mathrm{a}}$} \\
\hline Concurrent chemoradiotherapy & 6 \\
\hline Sequential chemoradiotherapy & 2 \\
\hline Radiotherapy alone & 1 \\
\hline \multicolumn{2}{|l|}{ Lung volume $(n=9)^{\mathrm{a}}$} \\
\hline Free breathing $(\mathrm{L})$ (mean) (range) & $4.1(2.1-5.7)$ \\
\hline Breath hold (L) (mean) (range) & $6.1(4.1-8.0)$ \\
\hline Relative increase (\%) (mean) (range) & $150(114-200)$ \\
\hline
\end{tabular}

FEV1: Forced expiratory volume in $1 \mathrm{~s}$.

${ }^{\mathrm{a}} 1$ patient was upstaged to stage IVc at planningCT and was not treated with RT.

lungs are not fully imaged on the daily CBCT due to the limited field-of-view. This daily AP distance was obtained by doing a $3 \mathrm{D} C B C T-C T$ match both on the spine and on the sternum, and subtracting the resulting $A P$ numbers from each other. Finally, the daily positions of the primary tumor were analyzed by measuring the displacement vector of the primary tumor relative to the matching structure (carina or bones). For this study, all CBCT matches were re-done offline.

\section{Results}

\section{Patients' characteristics \& feasibility}

Between March and December 2019, 10 NSCLC patients signed informed consent, but one was excluded after training session due to diagnosis of diffuse metastases on the planningCT. Table 1 shows patients' characteristics. Seven out of 9 patients $(78 \%)$ completed the whole treatment with NHFT as planned. The remaining two (22\%) (patients 1 and 5) asked for a FB treatment with the backup plan for 2 and 3 fractions, at a dose of $40 \mathrm{~Gy}$ and $54 \mathrm{~Gy}$, respectively, because of worsened condition due to chemoradiotherapy side effects.

\section{BH length}

During training session, the mean $\mathrm{BH}$ length without NHFT was $39 \mathrm{~s}$ (range 15-86s;SD $21 \mathrm{~s}$ ), and significantly increased with NHFT to $78 \mathrm{~s}$ (range 29-223s;SD $57 \mathrm{~s})(p=.005)$ (Figure
2). The $\mathrm{BH}$ duration increased by a mean factor of 2.1 (range 1.1-3.9; SD 0.9) with NHFT. Two out of 10 patients (20\%) were able to perform a $\mathrm{BH}$ of $>90 \mathrm{~s}$, and $5(50 \%)$ performed a $\mathrm{BH}$ of $>60 \mathrm{~s}$ with NHFT (Figure 2). The boxplots in Figure 2 represent the maximal $\mathrm{BH}$ length per session, and it shows that despite the different $\mathrm{BH}$ instructions, most patients can reproduce the $\mathrm{BH}$ length of the training session during treatment. The overall mean maximal $\mathrm{BH}$ length during treatment was $65 \mathrm{~s}$ (range 36-107s;SD $25 \mathrm{~s}$ ) (Figure 2). FEV1 did not correlate with $\mathrm{BH}$ length, both without and with NHFT (correlation coefficients: 0.2 and 0.1 , respectively) (Figure 2).

The mean number of $\mathrm{BH}$ s needed to perform one CBCT was 1.7 (range 1.2-2.5) and to deliver RT 3.7 (range 2.2-6.1). The mean beam-on time per fraction was $3.0 \mathrm{~min}$ (range 2.2-4.6 min). Individual patient data is shown in Supplementary file B.

\section{Stability and reproducibility}

Stability and reproducibility of all patients are represented in Figure 3. The mean and median overall stability were $0.34 \mathrm{~mm}$ and $0.33 \mathrm{~mm}$ respectively, range $0.17-0.49 \mathrm{~mm}$. The mean and median overall reproducibility were $0.43 \mathrm{~mm}$ and $0.45 \mathrm{~mm}$ respectively, range $0.17-0.68 \mathrm{~mm}$.

The average of the mean displacement vector of the primary tumor relative to the matching structure per patient was $1.8 \mathrm{~mm}$ (range $-1.1-8.1 \mathrm{~mm} ; \mathrm{SD} 2.4 \mathrm{~mm}$ ) (Figure $4(\mathrm{~A})$ ). These differences were $\leq 8 \mathrm{~mm}$ (which is the PTV margin for the primary tumor), except for patient 1 who had an outlier of $10 \mathrm{~mm}$, and patient 6 where differences up to $32 \mathrm{~mm}$ were seen due to atelectasis disappearance. Replanning resulted in small differences for the rest of the treatment.

The mean lung volume increased significantly from $4.1 \mathrm{~L}$ in $\mathrm{FB}$ to $6.1 \mathrm{~L}$ with $\mathrm{BH}(p=.008)$, with a relative increase of on average $150 \%$ (Table 1 ).

The interfractional difference in $\mathrm{BH}$ depth, based on the mean differences in AP match results (spine and sternum) per patient between planning $C T$ and daily $C B C T$, was on average $1.2 \mathrm{~mm}$ (range: $-1.6-4.2 \mathrm{~mm}$;SD $1.4 \mathrm{~mm}$ ) (Figure 4(B)).

\section{Subjective tolerance}

Overall, the subjective tolerance to the treatment was excellent (Supplementary file A). The majority of patients had no (score 0 ) or minor (score 1-2) discomfort throughout the treatment. Only two patients scored discomfort 3 at training session (because of the goggles, or a dry throat), and none had a score of 4 or 5 .

\section{Physiological parameters}

The average of the mean $\mathrm{tcpCO}_{2}$ per patient was $34 \mathrm{mmHg}$ (SD $3 \mathrm{mmHg}$;range $27-38 \mathrm{mmHg}$ ). The mean change in $\mathrm{tcpCO}_{2}$ per session (=maximum minus minimum) per patient was $6 \mathrm{mmHg}$ (SD $2 \mathrm{mmHg}$;range $4-8 \mathrm{mmHg}$ ). The average of the mean HR per patient was 79bpm (SD 6bpm;range 60-96bpm). The mean change in HR per session (maximum minus minimum) per patient was $13 \mathrm{bpm}$ (range 6-25bpm). 


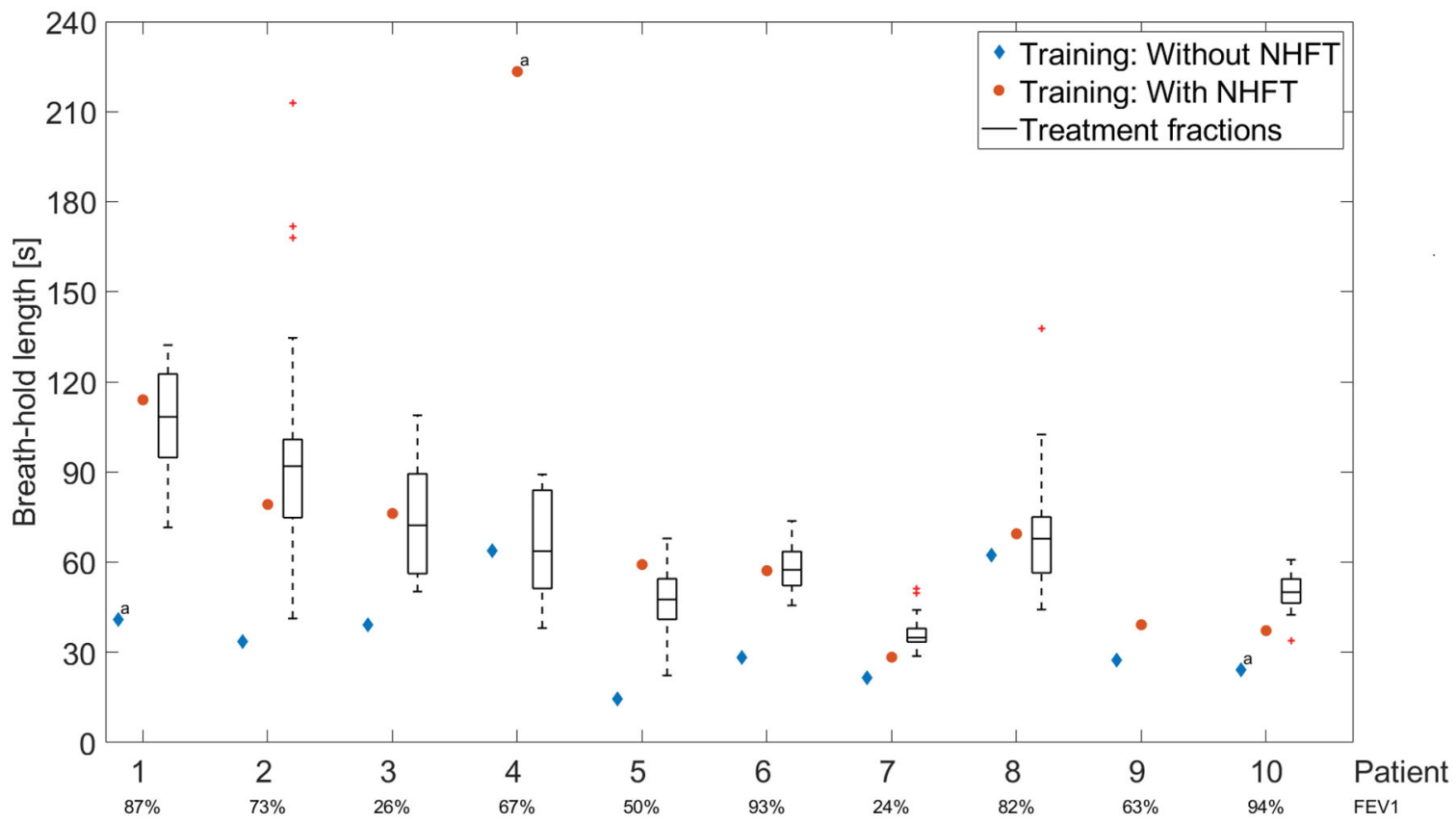

Figure 2. Maximal BH length during training session without (blue diamond) and with NHFT (red circles) per patient: instruction was to hold the breath as long as possible. Boxplots show the longest BH per fraction for the whole treatment per patient: instruction was to hold the breath as long as it felt comfortable and/or stable. FEV1 of each patient is shown below the graph. Patient 9 was excluded from the study after the training session. For patient 4, a NHFT BH extending to $223 \mathrm{~s}$ was observed, but this BH was unstable according to the OST signal, and may have been caused by the absence of the goggles for the patient for that BH. NHFT:

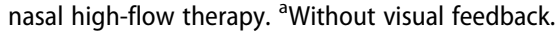

\section{Reproducibility}

Pt. 1

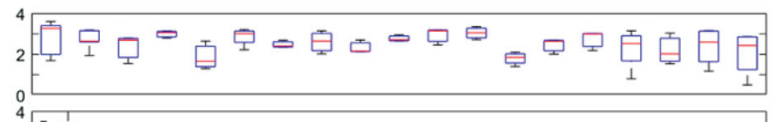

Pt. 2

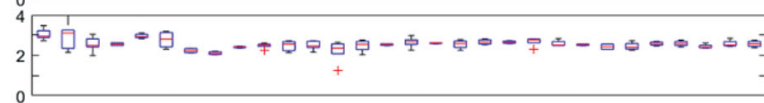

Pt. 3

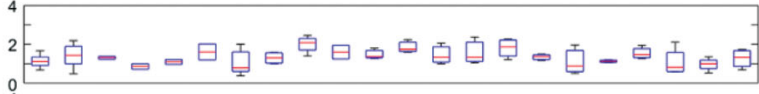

Pt. 4 它 $^{2}$

Pt. 5

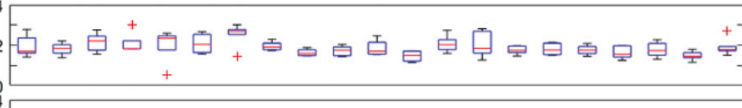

Pt. 6

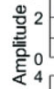

2

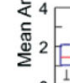

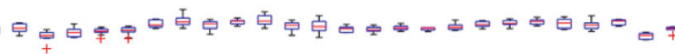

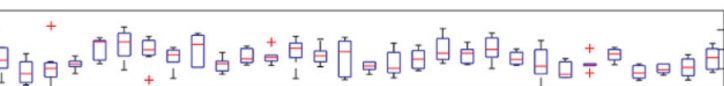

Pt. 7

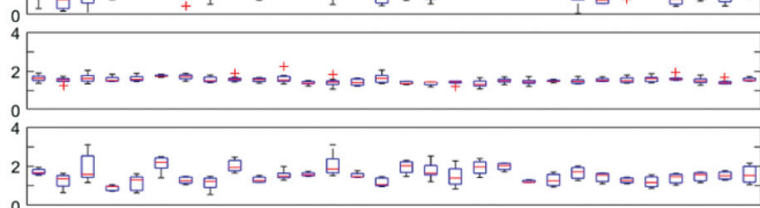

Pt. 8

Pt. 10

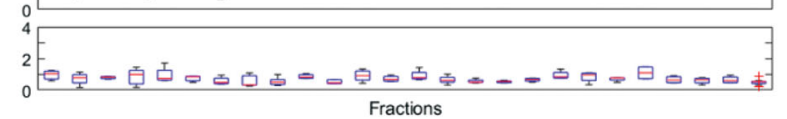

Stability

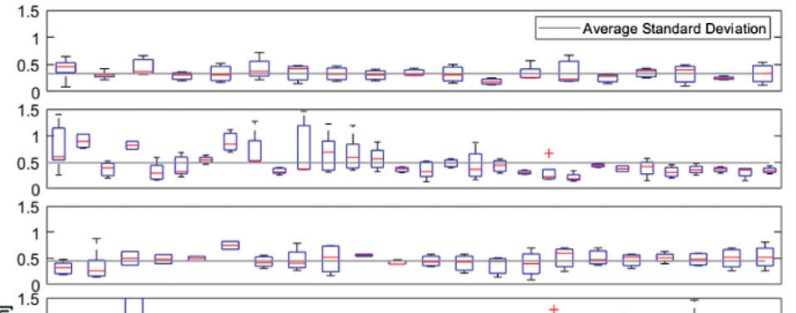

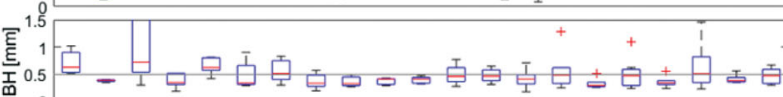

兽 1.5

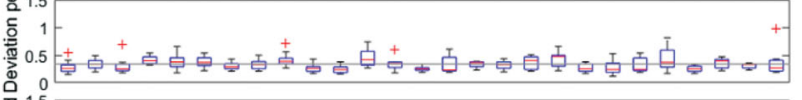

尊 1.5

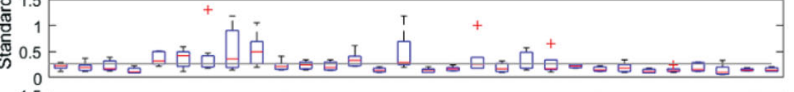

1.5

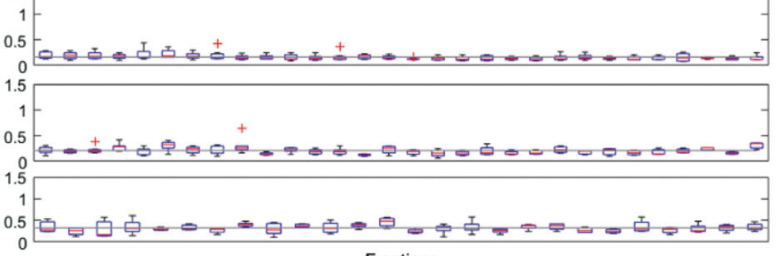

Fractions

Figure 3. Reproducibility and stability for 9 patients (patient 9 was excluded after the training session). Patients 7 and 8 have the most stable BHs, and patient 7 also has the most reproducible $\mathrm{BH}$ s as can be seen in the low variability within and between fractions. BH: breath-hold.

We did not observe significant desaturation, with mean minimum $\mathrm{SpO}_{2}$ ranging between 97-99\% (Supplementary file B).

\section{Discussion}

We showed that IBH supported with nasal high flow therapy (NHFT) in locally advanced NSCLC patients treated with RT was feasible, with $78 \%$ of patients completing the whole treatment as planned. Only two patients (22\%) were treated with the back-up FB plan for 2 and 3 fractions respectively. Because of chemoradiation side effects, they didn't feel well enough to perform several BHs. Furthermore, subjective tolerance to the treatment in our study was very good (Supplementary file A). Compared to other studies the compliance was higher. In the study of Giraud et al., a 
(A)
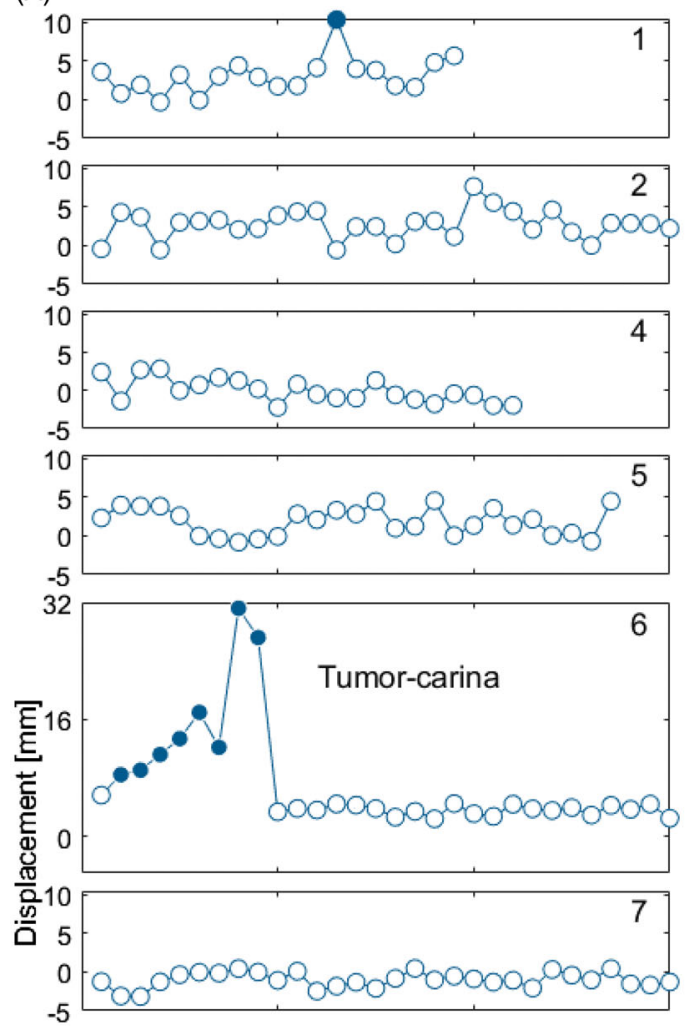

(B) Spine-Sternum Match - AP
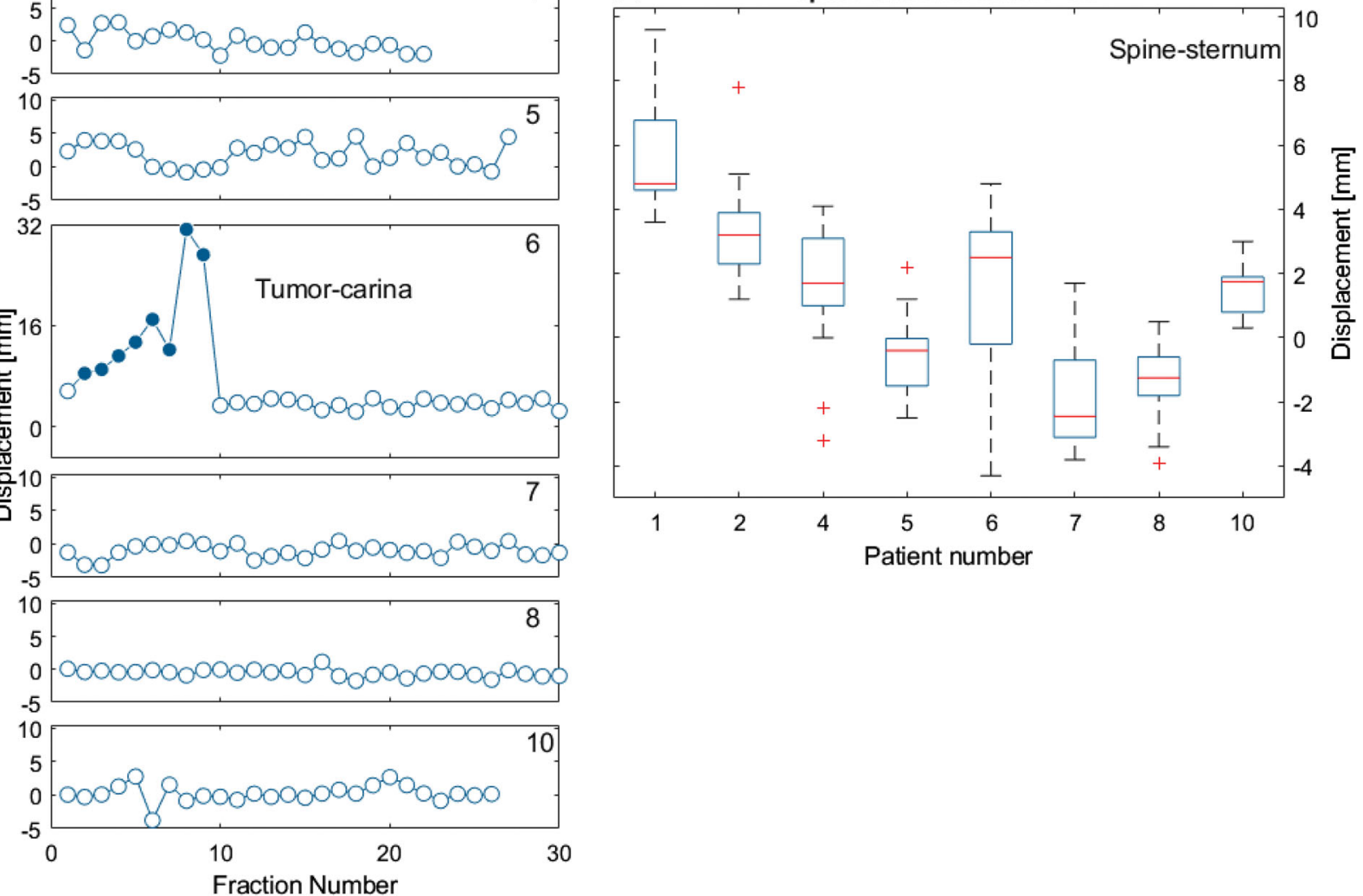

Patient number

Fraction Numbe

Figure 4. (A) $3 \mathrm{D}$ shift vectors of the primary tumor in eight patients for all fractions, obtained by calculating the difference between the daily $\mathrm{CBCT}$ match on carina (or bones for patient 1) and match on the primary tumor. Open dots are sessions with a shift of $\leq 8 \mathrm{~mm}$ and solid blue dots $>8 \mathrm{~mm}$. Patient 6 had sessions with a large shift in the first part of the treatment, due to disappearance of atelectasis. Patient 3 is not shown here because he had no primary tumor, only lymph nodes. (B) Difference in AP distance (spine-sternum 3 D match results) between daily CBCT and planning CT. This measure is considered a surrogate for the daily BH depth or lung volume.

compliance of $88 \%$ was reported using a spirometer for $\mathrm{BH}$, but according to their definition of compliance, this would be $100 \%$ in our study [4]. Josipovic et al. reported that $86 \%$ could start visually-guided IBH treatment, and 63\% terminated the whole treatment as planned [18].

In general, reported $\mathrm{BH}$ durations are rather short, around $20 \mathrm{~s}$, resulting in many BHs per session and longer treatment sessions [7]. During training sessions the mean maximal BH duration in our study increased significantly from $39 \mathrm{~s}$ without to $78 \mathrm{~s}$ with NHFT (Figure 2), with an increase of on average factor 2.1. Half of the patients were even able to hold their breath for more than one minute. Most patients were able to reproduce the $\mathrm{BH}$ length from the training session during treatment, despite the different $\mathrm{BH}$ instructions between training and treatment (Figure 2). In some patients, there was even an increased $\mathrm{BH}$ length during treatment, suggesting a learning curve.

Potential explanations why addition of nasal airflow with extra oxygen through a nasal cannula worked, can be found in the study of Parke et al. [19], where with NHFT through a nasal cannula in healthy volunteers, the airway pressures and the end-expiratory lung volumes increased, suggesting that with high flows the functional residual capacity increases. Another potential explanation is the washout of $\mathrm{CO}_{2}$ in $\mathrm{BH}$ caused by the high airflow, resulting in suppression of the breath stimulus.

The mean overall stability and reproducibility measured with OST were within $1 \mathrm{~mm}$ (Figure 3). For stability, the median SD of the BH level was $0.33 \mathrm{~mm}$. Regarding reproducibility, the median SD of the mean amplitudes was $0.43 \mathrm{~mm}$.

Because an external marker is not always a good surrogate for the daily position of the lung tumor, we measured the daily lung tumor position on the CBCT relative to the matching structure [20]. Overall, we found an acceptable reproducibility with a mean change in tumor position of $1.8 \pm 2.4 \mathrm{~mm}$. In the majority of the sessions the displacement was within the PTV margin of $8 \mathrm{~mm}$, except for one patient where an atelectasis disappeared causing a primary tumor 
shift (Figure 4(A)). Inter-fraction variability for the tumor position has previously mainly been evaluated on a few (often 3 to 5) repeated CT scans, whereas in our study we evaluated the position of the primary tumor in all treatment fractions [18,21-24]. Brock et al. reported a mean interfraction change in tumor position between pretreatment and midtreatment of $5.1 \mathrm{~mm}(\mathrm{CC}), 3.6 \mathrm{~mm}$ (LR) and $3.5 \mathrm{~mm}$ (AP), with the largest difference $16.6 \mathrm{~mm}$ [25]. In the pilot study of Josipovic et al., the median differences in tumor position between $3 \mathrm{BH} C T$ s were $2.5 \mathrm{~mm}, 4.1 \mathrm{~mm}$ and $2.4 \mathrm{~mm}$, and in their subsequent study with 72 patients, $1.0 \mathrm{~mm}, 0.9 \mathrm{~mm}$ and $1.3 \mathrm{~mm}$, respectively $[18,22]$. All these studies, including ours, used a visual feedback system as it has been shown to increase reproducibility not only for $\mathrm{FB}$, but also for $\mathrm{BH}$ treatments $[26,27]$.

Unfortunately, we have no information on the intra-fraction tumor position changes, as we did not use imaging during or immediately after delivery. Other studies showed that $\mathrm{IBH}$ reduces, but not eliminates tumor motion, and that tumor motion can be influenced by cardiac motion $[21,23,28]$. Yoshitake et al. showed a low residual motion of the tumor $(1.3 \mathrm{~mm}(\mathrm{LR}), 1.5 \mathrm{~mm}(\mathrm{AP})$ and $2.0 \mathrm{~mm}(\mathrm{CC}))$ in 16 lung cancer patients treated with stereotactic ablative radiotherapy in visually-guided $\mathrm{BH}$ [23]. Rydhog et al. found similar numbers in locally advanced lung cancer patients with residual motions of $1.4 \mathrm{~mm}, 1.2 \mathrm{~mm}$ and $2.1 \mathrm{~mm}$, measured during visually guided $\mathrm{BH}$ through implanted liquid markers injected in lymph nodes or tumors [21]. Furthermore, IBH significantly reduced marker movements, and this movement was not significantly different anymore between fractions compared with FB [21].

In our study, PTV margins were still comparable to those used in FB treatments. But when considering reducing the PTV-margins for treatments in $\mathrm{BH}$, this residual motion has to be taken into account. Interestingly, also the intrafractional baseline shifts reported by Rydhog et al. were very small with means of $-0.3 \mathrm{~mm}$ (AP), $0.0 \mathrm{~mm}$ (LR) and $0.5 \mathrm{~mm}$ (CC) with total time between measurements around $15 \mathrm{~min}$ [21]. In both studies the $\mathrm{BH}$ length was only around $20 \mathrm{~s}$, raising the question whether these results can be extrapolated to longer $\mathrm{BHs}$. Since the $\mathrm{BH}$ durations in our study were only a bit longer, around $1 \mathrm{~min}$, it seems therefore acceptable to do so. However, for longer $\mathrm{BHs}$ of 5 to $20 \mathrm{~min}$ as studied by several other groups, this question is more pressing $[9,11,28]$.

Audiovisual feedback not only improves the reproducibility, but also the consistency of a $\mathrm{BH}$, being the differences in lung volumes per $\mathrm{BH}$ [26]. Because the lungs are not fully imaged on the daily CBCTs we measured in $3 \mathrm{D}$ the AP distance between spine and sternum as a surrogate for the lung volume, and showed reproducible $\mathrm{BH}$ depths (mean $1.2 \mathrm{~mm}$, range $-1.6-4.2 \mathrm{~mm}$ ), except for patient 1 where a systematically deeper $\mathrm{BH}$ was seen compared with the planning $C T$ (Figure 4(B)).

To evaluate the safety during NHFT, we monitored $t p \mathrm{CO}_{2}$, heart rate and $\mathrm{SpO}_{2}$, and changes in these parameters per fraction. Although the parameters could vary within a fraction, they remained within normal limits. One of the limitations of this study is that we did not measure the blood pressure during training session or treatment. Parkes et al. has shown that with prolonged $\mathrm{BHs}$, systolic blood pressure may rise without change in heart rate and this rise cannot be prevented by pre-oxygenation [12]. Therefore, caution has to be taken in patients with cardiovascular morbidity, especially when longer $\mathrm{BH}$ of several minutes are performed [10].

We chose a simple method (Optiflow $^{\mathrm{TM}}$ nasal high flow therapy) that is cheap, easy to use and simple to implement. Moreover, the flow is administered through a nasal cannula and not through a face mask, which is less cumbersome for patients. And since $\mathrm{BH}$ s were stable and reproducible, we believe that with several $\mathrm{BHs}$ per session a high treatment accuracy can be achieved, especially in proton treatments for non-small cell lung cancer with large tumor motion in FB. With protons, anatomy shifts due to breathing can lead to considerable over- or underdosage because the proton range is much more sensitive to density changes compared with photons $[5,29,30]$.

In conclusion, NHFT for BH in RT treatment of NSCLC is feasible and well tolerated, even without extensive training, and significantly increased the $\mathrm{BH}$ duration. Visually guided $\mathrm{BH}$ s with surface scanning were stable and reproducible. Furthermore, this technique is easy to use by radiotherapy technicians, comfortable for patients and not expensive. We therefore consider this an attractive approach to irradiate lung cancer patients in $\mathrm{IBH}$ that can be introduced in daily clinical practice, both for photon and proton therapy.

\section{Acknowledgments}

The authors want to thank Ruud Houben for his very valuable contribution to the statistical analyses.

\section{Disclosure statement}

Dr. De Ruysscher reports grants from BMS, grants from AstraZeneca, Celgene, Merck/Pfizer, Seattle Genetics, Roche/Genentech, Philips, Olink and Noxxon, outside the submitted work.

Dr. Peeters reports non-financial support from Fisher \& Paykel, nonfinancial support from Radiometer, during the conduct of the study.

All other coauthors have nothing to disclose.

\section{Data availability statement}

Research data are stored in an institutional repository and will be shared upon request to the corresponding author.

\section{References}

[1] Wolthaus JWH, Sonke JJ, van Herk M, et al. Comparison of different strategies to use four-dimensional computed tomography in treatment planning for lung cancer patients. Int J Radiat Oncol Biol Phys. 2008;70(4):1229-1238.

[2] Boda-Heggeman J, Knopf A-C, Simeonova-Chergou A, et al. Deep inspiration breath hold-based radiation therapy: a clinical review. Int J Radiat Oncol Biol Phys. 2016;94(3):478-492.

[3] Appelt AL, Vogelius IR, Farr KP, et al. Towards individualized dose constraints: adjusting the QUantec radiation pneumonitis model for clinical risk factors. Acta Oncol. 2014;53(5):605-612.

[4] Giraud P, Morvan E, Claude L, STIC Study Centers, et al. Respiratory gating techniques for optimization of lung cancer radiotherapy. J Thorac Oncol. 2011;6(12):2058-2068. 
[5] Bert C, Grözinger SO, Rietzel E. Quantification of interplay effects of scanned particle beams and moving targets. Phys Med Biol. 2008;53(9):2253-2265.

[6] Panakis N, McNair HA, Christian JA, et al. Defining the margins in the radical radiotherapy of non-small cell lung cancer (NSCLC) with active breathing control $(A B C)$ and the effect on physical lung parameters. Radiother Oncol. 2008;87(1):65-73.

[7] McNair HA, Brock J, Symonds-Tayler JR, et al. Feasibility of the use of the Active Breathing Co ordinator (ABC) in patients receiving radical radiotherapy for non-small cell lung cancer (NSCLC). Radiother Oncol. 2009;93(3):424-429.

[8] Wilson EM, Williams FJ, Lyn BE, et al. Validation of active breathing control in patients with non-small-cell lung cancer to be treated with CHARTWEL. Int J Radiat Oncol Biol Phys. 2003;57(3): 864-874.

[9] Peguret N, Ozsahin M, Zeverino M, et al. Apnea-like suppression of respiratory motion: first evaluation in radiotherapy. Radiother Oncol. 2016;118(2):220-226.

[10] Parkes MJ, Green S, Stevens AM, et al. Safely prolonging single breath-holds to $>5 \mathrm{~min}$ in patients with cancer; feasibility and applicatioins for radiotherapy. BJR. 2016;89(1063):20160194.

[11] Parkes MJ, Green S, Kilby W, et al. The feasibility, safety and optimization of multiple prolonged breath-holds for radiotherapy. Radiother Oncol. 2019;141:296-303.

[12] Parkes MJ, Green S, Stevens AM, et al. Assessing and ensuring patient safety during breath-holding for radiotherapy. BJR. 2014; 87(1043):20140454.

[13] Parke R, McGuinness S, Eccleston M. Nasal high-flow therapy delivers low level positive airway pressure. $\mathrm{Br} J$ Anaesth. 2009; 103(6):886-890.

[14] Schmid F, Olbertz DM, Ballmann M. The use of high-flow nasal cannula (HFNC) as respiratory support in neonatal and pediatric intensive care units in Germany - a nationwide survey. Respir Med. 2017;131:210-214.

[15] Pilcher J, Eastlake L, Richards M, et al. Physiological effects of titrated oxygen via nasal high-flow cannulae in COPD exacerbations: a randomized controlled cross-over trial. Respirology. 2017; 22(6):1149-1155.

[16] Fraser JF, Spooner AJ, Dunster KR, et al. Nasal high flow oxygen therapy in patients with COPD reduces respiratory rate and tissue carbon dioxide while increasing tidal and end-expiratory lung volumes: a randomised crossover trial. Thorax. 2016;71(8): 759-761.

[17] A'Hern RPA. Sample size tables for exact single-stage phase II designs. Stat Med. 2001;20(6):859-866.
[18] Josipovic M, Aznar MC, Thomsen JB, et al. Deep inspiration breath hold in locally advanced lung cancer radiotherapy: validation of intrafractional geometric uncertainties in the INHALE trial. BJR. 2019;92(1104):20190569.

[19] Parke RL, Bloch A, McGuinness SP. Effect of very-high-flow nasal therapy on airway pressure and end-expiratory lung impedance in healthy volunteers. Respir Care. 2015;60(10):1397-1403.

[20] Hazelaar C, Dahele M, Mostafavi $H$, et al. Markerless positional verification using template matching and triangulation of $\mathrm{kV}$ images acquired during irradiation for lung tumors treated in breath-hold. Phys Med Biol. 2018;63(11):115005.

[21] Rydhög JS, Riisgaard de Blanck S, Josipovic M, et al. Target position uncertainty during visually guided deep-inspiration breathhold radiotherapy in locally advanced lung cancer. Radiother Oncol. 2017;123(1):78-84.

[22] Josipovic M, Persson GF, Dueck J, et al. Geometric uncertainties in voluntary deep inspiration breath hold radiotherapy for locally advanced lung cancer. Radiother Oncol. 2016;118(3):510-514.

[23] Yoshitake T, Shioyama Y, Nakamura K, et al. A clinical evaluation of visual feedback-guided breath-hold reproducibility of tumor location. Phys Med Biol. 2009;54(23):7171-7182.

[24] Seppenwoolde $Y$, Shirato $H$, Kitamura K, et al. Precise and realtime measurement of 3D tumor motion in lung due to breathing and heartbeat, measured during radiotherapy. Int J Radiat Oncol Biol Phys. 2002;53(4):822-834.

[25] Brock J, McNair HA, Panakis N, et al. The use of the Active Breathing Coordinator throughout radical non-small-cell lung cancer (NSCLC) radiotherapy. Int J Radiat Oncol Biol Phys. 2011; 81(2):369-375.

[26] Lee D, Greer P, Lapuz C, et al. Audiovisual biofeedback guided breath-hold improves lung tumor position reproducibility and volume consistency . Adv Radiat Oncol. 2017;2(3):354-362.

[27] Lee D, Greer PB, Paganelli C, et al. Audiovisual biofeedback improves the correlation between internal/external surrogate motion and lung tumor motion. Med Phys. 2018;45(3):1009-1017.

[28] Audag N, Van Ooteghem G, Liistro G, et al. Intrapulmonary percussive ventilation leading to 20 -minutes breath-hold potentially useful for radiation treatments. Radiother Oncol. 2019;141: 292-295.

[29] Jakobi A, Perrin R, Knopf A, et al. Feasibility of proton pencil beam scanning treatment of free-breathing lung cancer patients. Acta Oncol. 2018;57(2):203-210.

[30] Gorgisyan J, Munck A, Rosenschold P, et al. Feasibility of pencil beam scanned intensity modulated proton therapy in breathhold for locally advanced non-small cell lung cancer. Int J Radiat Oncol Biol Phys. 2017;99(5):1121-1128. 